\title{
Development of the DAGIS intervention study: a preschool-based family-involving study promoting preschoolers' energy balance-related behaviours and self- regulation skills
}

Carola Ray ${ }^{1,2^{*}}$ (D), Riikka Kaukonen ${ }^{1,2}$, Elviira Lehto ${ }^{1,3}$, Henna Vepsäläinen², Nina Sajaniemi ${ }^{3,4}$, Maijaliisa Erkkola ${ }^{2}$ and Eva Roos ${ }^{1,2,5}$

\begin{abstract}
Background: Preschoolers' energy balance-related behaviours (EBRBs) and self-regulation skills are important for their later health. Few preschool-based interventions aiming to promote preschoolers' EBRBs and self-regulation skills, simultaneously reducing differences in EBRBs, due to children's socio-economic status (SES) background, have been conducted. This study will present the Increased Health and Wellbeing in Preschools (DAGIS) intervention development process applying the Intervention Mapping (IM) framework.

Methods: The development of the DAGIS intervention study, a preschool level clustered randomized controlled trial $(\mathrm{RCT})$, was based on the IM framework. The protocol in IM guides the development process of an intervention through six steps: needs assessment and logic model of the problem, programme outcomes and objectives, design of the programme, production, implementation plan, and evaluation plan.

Results: The needs assessment, part of the step 1 in IM, yielded the base for the DAGIS logic model of change. The model includes objectives related to changes in children's EBRBs, self-regulation skills, and in psychosocial and physical environment that is determined by parents and early educators. A 22-week programme was developed, and materials for preschools and families were produced. A feasibility study of the recruitment processes, acceptability of the materials and methods, and implementation was conducted. The DAGIS intervention study was conducted September 2017-May 2018 as a clustered RCT including a comprehensive effectiveness and process evaluation. The process evaluation was run throughout the intervention targeting preschools and families.

Conclusion: A preschool-based family-involving programme was developed in the DAGIS intervention study by applying the IM protocol. It was a time- and resource-consuming process. However, the systematic planning, development, and running of the programme have reinforced a comprehensive evaluation, which is a strength in the intervention. The results from the evaluation will enhance the knowledge of how to promote EBRBs and self-regulation skills among preschoolers, and diminish SES differences in them.
\end{abstract}

Trial registration: ISRCTN57165350 (Prospectively registered January the 8th, 2015).

(Continued on next page)

\footnotetext{
* Correspondence: carola.ray@folkhalsan.fi

${ }^{1}$ Folkhälsan Research Center, Topeliuksenkatu 20, 00250 Helsinki, Finland

${ }^{2}$ Department of Food and Nutrition, University of Helsinki, P.O. Box 66, 00014

Helsinki, Finland

Full list of author information is available at the end of the article
}

(c) The Author(s). 2019 Open Access This article is distributed under the terms of the Creative Commons Attribution 4.0 International License (http://creativecommons.org/licenses/by/4.0/), which permits unrestricted use, distribution, and

reproduction in any medium, provided you give appropriate credit to the original author(s) and the source, provide a link to the Creative Commons license, and indicate if changes were made. The Creative Commons Public Domain Dedication waiver (http://creativecommons.org/publicdomain/zero/1.0/) applies to the data made available in this article, unless otherwise stated. 
(Continued from previous page)

Keywords: Intervention development, Intervention mapping, Energy balance-related behaviours, Physical activity, Food consumption, Screen time, Self-regulation skills, Preschoolers, Socio-economic differences in health behaviours,

Preschool-based family-involving intervention

\section{Background}

Children's physical activity (PA), sedentary behaviour, and food consumption are commonly called energy balancerelated behaviours (EBRBs). EBRBs and stress regulation are important for children's current and future health and wellbeing [1-3]. Previous studies show that a socioeconomic status (SES) gradient exists at least in some of children's EBRBs. Children from low SES backgrounds have more screen time [4], less PA [5, 6], and lower intake of fruit and vegetables $[4,7]$. Some studies show an association between children's low SES backgrounds and higher stress levels [8].

In order to promote children's further health and wellbeing it is important to focus on promoting children's healthy EBRBs, as well as lower the effects of stress. It has been shown that self-regulation skills are highly linked to stress levels, and therefore strengthening children's self-regulation skills should be given high priority when aiming to diminish stress levels in children $[9,10]$. Self-regulation as a concept is multidimensional, and it has been described as a construct including both emotional and behavioral self-regulation [10]. Shortly described, emotional self-regulation is the capacity to be able to recognize own feelings and stay calm in stressful situations, whereas behavioral selfregulation relates to impulsivity, or inhibitory control $[9,10]$. Poor self-regulation skills have been associated with less favorable EBRBs, such as higher intake of palatable food, or using food as a reward, and further with higher BMI later in life [11, 12]. Recently, it has been proposed that strengthening children's self-regulation skills, along with the promotion of healthy EBRBs, leads to more efficient results in children's EBRBs, as well as a healthy weight, than by only promotion healthy EBRBs [9, 13]. The approach to promote children's healthy EBRBs and simultaneously strengthening children's self-regulation skills, has been applied at least in one intervention study [10]. In general, the effects on children's EBRBs were not significant in the study, although the sugary drink consumption decreased more among those belonging to the intervention arm that simultaneously promoted healthy EBRBs, and strengthened self-regulation skills, compared to the other intervention arms in which both components were not included [10]. One explanation to the poor effects could be that families were not engaged enough in the preschool intervention. Family engagement in preschool interventions has been emphasized in reviews as a crucial part for successful interventions in children [14]. Another prominent aspect when conducting interventions including families is the SES gradient, which exists in children's EBRBs [4-7]. In the intervention planning phase, the researchers should try to plan activities, which are able to reach those who need it most, in this case families with low SES backgrounds, and further on reduce the SES differences in EBRBs. In order to avoid stigmatization based on SES in a population wide intervention, an appropriate way might be to apply the proportionate universalism approach [15]. In this approach, the intervention is delivered to the whole target population in a similar manner, and the intensity of the intervention is adjusted according to the needs of children from low SES backgrounds [15]. Few intervention studies have focused on narrowing SES differences in young children's EBRBs [16, 17].

In Finland, early childhood education and care centres, hereafter preschools, are good arenas to promote children's EBRBs and strengthen self-regulations skills. Most preschools are municipality-driven and open for all children. About $86 \%$ of all 5 -year-olds attend preschool in Finland, the percentages being slightly lower among 4and 3-years old, about 83 and $78 \%$ respectively [18]. Children usually attend a preschool near their home independently of their SES background, which means that most preschools have children with diverse SES backgrounds. Therefore preschools have huge possibilities to act as health-promoting arenas, and narrowing possible SES differences in children's EBRBs and stress regulation. The current National Core Curriculum for Early Childhood Education and Care 2016 emphasizes that preschools, in collaboration with families, should promote children's health behaviours and wellbeing [19]. The food recommendations for early childhood education and care, as well as the recommendations for physical activity in early childhood, are emphasizing the preschools' role in promoting EBRBs [20, 21].

Even though an arena for reaching many children with mixed SES background exists, the intervention planning still needs to be carefully conducted. Kok et al. [22] have proposed that effective interventions need to fulfil three conditions. Firstly, the intervention needs to target a determinant that is predicting the behaviour that the intervention aims to change. Secondly, the intervention should be able to change the determinant. Thirdly, the intervention needs to be conducted in a way that parameters are preserved in the practical application. The practical application 
should be accepted by the target population, considering the culture and the context in which it is conducted. In the Medical Research Council (MRC) guide for developing complex interventions, it emerges that there is a need for deeper work in the early stages of intervention planning [23]. The MRC guide emphasizes that there is a need to take the local context into account in the development of the intervention and piloting is an important phase in order to develop a successful complex intervention. A complex intervention is a programme that includes several interacting components, a high number of behaviours, and targets several levels of organizations [23]. Durlak and DuPre [24] concluded in their meta-analysis that the context and readiness of the implementers are relevant for successful implementation of interventions, and should be measured. Still, process evaluations have often been small-scale alongside effect evaluations, and knowledge of the crucial factors for a high-degree implementation of an intervention in the preschool and family setting is scarce [24]. A useful tool for developing complex interventions is the Intervention Mapping (IM) protocol, which enables a systematic way of designing, implementing and evaluating an intervention [22]. The planning process should be based on theoretical, empirical and practical information. The IM protocol is comprised of six steps: 1) needs assessment; 2) forming change objectives and model of change; 3 ) designing a programme; 4) producing materials; 5) planning, adoption, and implementation; and, 6) evaluation of the intervention [25]. The IM protocol states that the first two steps are of utmost importance.

The Increased Health and Wellbeing in Preschools project (hereafter called the DAGIS project) emerged from the knowledge of SES differences in preschoolers' with overweight and obesity in Finland [26]. A longterm goal of the DAGIS project is to diminish SES differences in weight status among preschoolers. The main aim for the DAGIS intervention study, here presented, is to promote preschoolers' EBRBs and strengthen selfregulation skills simultaneously reducing SES differences in them. A useful approach for an intervention, which includes all children independently of SES background, and simultaneously reduces SES differences, is the proportionate universalism approach [15]. Briefly, those with the highest needs should benefit most from the intervention [15]. The objectives of this paper are to present the planning process of the DAGIS intervention study, and to describe how the IM protocol has been applied throughout the DAGIS project.

\section{Methods}

In this paper, the methods section will shortly describe the six steps in the IM protocol [25], and briefly, which are the corresponding steps in the DAGIS intervention study. The results section describes the main results yielded in each step of the DAGIS intervention development. It also presents how the results were used in moving forward on the IM protocol steps.

\section{Steps 1 and 2: understanding the problem and determining the theory and evidence base}

The aims of the first and second steps in IM are to better understand the problem at hand, to identify key behaviours and their determinants related to the problem, and to specify the objectives for change [25]. In the DAGIS study, a comprehensive needs assessment with two central aims was conducted:

1) Gain insight into environmental barriers and facilitators related to preschool children's EBRBs and stress regulation specifically in the Finnish context

2) Explore EBRBs and stress regulation and their determinants in which SES differences exist among Finnish preschoolers.

A DAGIS socio-ecological model for children's EBRBs was developed in early stages of the project [27]. The model was used as a guiding tool when planning the comprehensive needs assessment. The needs assessment in the DAGIS study included three steps: 1 ) focus group interviews, 2) an informal literature review and 3) a cross-sectional survey. The steps all examined preschool children's PA, sedentary behaviour, screen time, dietary behaviour, stress regulation and factors related to EBRBs. A steering group for DAGIS was established. The group members were stakeholders with different backgrounds, including directors of early education, preschool managers, early educators, researchers, and representatives of Finnish parents' league (representing parents), children's health-promoting organizations, and health promoters in the field of young children. The steering committee met up about twice a year. Proceedings and obstacles in the DAGIS study were discussed, and knowledge and experiences were shared.

The focus group interviews in autumn 2014 were carried out in areas where, according to municipality statistics, a slightly higher proportion of the inhabitants had lower SES backgrounds. The interviews were conducted separately with parents of preschool-aged children (6 groups, total $n=17$ ) and early educators (4 groups, total $n=17$ ). The focus groups shed light on early educators' and parents' thoughts on their own roles in influencing children's EBRBs, as well as important barriers and facilitators for these behaviours. The focus group interviews have been presented in more detail in two published articles $[28,29]$. The informal literature review updated the research group about children's EBRBs, determinants for children's EBRBs, and the EBRBs where SES differences 
exist. It also provided knowledge on previous interventions carried out in preschool settings with similar aims. The cross-sectional survey was conducted between autumn 2015 and spring 2016 in eight municipalities in southern and western Finland, with 66 preschools, and 864 participants. The survey comprehensively elaborated the current state of PA (measured by accelerometers for 7 consecutive days), sedentary behaviour (accelerometers), screen time (7-day screen time diary recorded by parents), dietary intake (food frequency questionnaire and 3-day food records), children's temperament (Children's Behavior Questionnaire- the very short form) [30], children's stress levels (long-term measured via hair cortisol concentration, short-term stress measured via salivary cortisol-, and alpha-amylase), and their determinants among Finnish preschoolers [31]. In addition, the survey provided data on socio-economic differences in children's EBRBs, and explored psychosocial and physical environmental determinants for EBRBs. Mediation analyses were planned to be conducted in order to explore which determinants are of importance for the associations between low family SES and children's EBRBs. The analyse plans for the survey data also included moderation analysis to explore whether family SES moderated the associations between determinants for children's EBRBs and children's EBRBs. The examined themes for the survey were derived from the DAGIS socio-ecological model [27], the focus groups, and the existing literature.

Objectives for children's and parents' behaviour changes were identified, and a logic model for change was developed based on the findings. Literature was reviewed with a focus on behaviour-change theories that have shown to be useful and effective in interventions conducted in preschool settings. The logic model of change was complemented with constructs that were identified as essential according to the selected behavioural theories.

\section{Steps 3 and 4: designing the DAGIS programme and producing programme materials}

In the third step of the IM protocol, the aim is to design and create the actual concrete programme: its themes, components, and general structure [32]. Furthermore, the third step includes decisions about which behaviourchange methods are used and what kinds of practical applications they are turned into. In the fourth step of the IM protocol, the aim is to refine the programme design and components, if needed, and produce the programme materials.

In accordance with the third step, the contents, components, and structure of the DAGIS programme were designed during autumn 2016 and spring 2017. The process included four main methods: 1) workshops for parents and early educators, 2) workshops for the steering group,
3) an informal literature review, and 4) feasibility testing of the chosen strategies and materials.

The parents' and early educators' workshops were conducted in autumn 2016. Altogether eight workshops were held, of which two were only for early educators, two only for parents, and four both for parents and early educators together. The aim of the workshops was to gather participants' ideas about what could be done in real life to promote healthy habits at home and at preschool, and what kind of delivery methods and materials would be suitable and acceptable to them. During a steering group meeting, group members attended workshops in which they could generate ideas about how to successfully recruit families to the intervention study, and share thoughts about appealing materials and methods for the intervention. The aim of the informal literature review was to identify effective behaviour-change methods and suitable practical applications to be adapted to the DAGIS programme. The review included searching through the international scientific literature as well as mapping out materials produced by other national health-promoting organizations. Some materials were developed specifically for the DAGIS programme because suitable materials for influencing all targeted determinants did not exist. The feasibility tests of developed materials and methods were conducted in June 2017 in two preschools. Parents $(n=19)$ provided feedback regarding developed materials and methods through questionnaires. Early educators $(n=$ 4) gave their feedback by informal interviews. Simultaneously, recruitment procedures for the study, and feasibility of the evaluation questionnaires were tested in five additional preschools. Feedback related to the planned family recruitment process was received through an early educator's informal interview in one of the preschools. Feasibility of the planned evaluation questionnaires was assessed based on the questionnaire responses received (parents' questionnaires $n=$ 16; early educators' questionnaires $n=11$ ).

\section{Step 5: planning adoption and implementation}

The purpose of the fifth step in the IM protocol is to plan: 1) how people who adopt and implement the programme can be motivated to take it up and engage in the activities; 2) materials and programme objectives; and, 3) how to maintain the programme [25].

Adoption and implementation of the DAGIS intervention were planned simultaneously with the intervention design and materials. The literature was analysed with a focus on early educators' motivation and training because they were recognized key people for the implementation of the DAGIS intervention. The DAGIS steering group included experts from the field of early 
childhood education who added valuable knowledge about adoption and implementation of interventions in preschool settings. The feasibility testing in step 4 added information on adoption and implementation of the programme.

\section{Step 6: evaluation}

In the last step of the IM protocol, the evaluation should be planned [25]. Programme effectiveness and the process should be evaluated [25]. Evaluation of the DAGIS intervention was planned in tandem with the development of the programme, and refined and finalized as the programme was running. The evaluation of the effectiveness was planned based on the logic model of change formed in step 2. The DAGIS intervention study was conducted as a preschool level clustered randomized controlled trial. Power calculations based on results from the DAGIS crosssectional survey were made to obtain the needed sample size to detect changes in children's EBRBs. The RE-AIM (reach, effectiveness, adoption, implementation and maintenance) framework was a crucial guiding tool in planning the evaluation [33]. The DAGIS intervention also applied several other frameworks and guidances in designing the process evaluation [23, 34-36]. The process evaluation focused on the activities and inputs in the intervention, and the implementation process. The DAGIS intervention study was approved as ethically acceptable by the University of Helsinki Ethical Review Board in Humanities and Social and Behavioral Sciences in May 2017 (22/2017).

\section{Results}

This section describes results gained in each step of the planning process and how the results have been applied in the DAGIS intervention development.

Results in steps 1 and 2: understanding the problem and determining the theory and evidence base for the DAGIS intervention

\section{Factors influencing preschool children's health behaviours} and barriers to change

The focus groups yielded valuable knowledge about the home and preschool context as promoters or barriers for EBRBs and results have been reported in detail elsewhere $[28,29]$. Parents talked about themselves as role models for both PA and intake of sugary foods and drinks. Parents also described that their children consumed many sugary foods daily. Still, when asking them, they were not concerned about the fairly high sugar intake. Parents did not either see a problem in their children not being physically active enough. Early educators recognized that excessive sitting time existed at preschool. Still, many early educators felt that it was an important task to teach children to sit because children need this skill in school. Early educators acknowledged themselves as role models for PA, especially when outdoors. However, many mentioned that they do not have the time to act as role models, or they are not motivated to encourage PA, as children were physically active without any encouragement [28]. Focus group results were applied when designing the questionnaires for the comprehensive survey and the intervention measurements. Further, the results were utilized for development work of the logic model of change and when designing the programme and its contents.

\section{Socio-economic differences in children's health behaviours and stress}

In the cross-sectional survey, the family SES was assessed comprehensively, and the results of SES differences in children's EBRBs have been reported in detail elsewhere [31]. Lower parental education (answering parent) was associated with children's higher screen time (measured by a 7 day screen time diary), a more frequent consumption of sugar-sweetened beverages and sugary everyday foods e.g. flavoured yoghurts and quarks, sugar-sweetened cereals, measured by a food frequency questionnaire [31]. Measuring food intake by 3-day food records showed that children whose parent was lower educated (high school level or lower education) ate fewer vegetables (in grams) than children whose parent had a master's degree or higher education [31]. The DAGIS survey did not show any SES differences in children's long-term stress, which was measured by analysing hair samples from each child (cortisol concentrations).

The literature review supported the survey findings of less beneficial EBRBs among children from low SES backgrounds, and most evident SES differences were found in sugary food and beverage consumption $[4,7,37]$, and in screen time $[4,38,39]$. The literature review also indicated SES differences in children's fruit and vegetable intake [4, 7]. Furthermore, the literature review showed that a low SES background predisposed children to higher stress levels [8], and different stress measures were shown to have an adverse association to health behaviours and weight $[2,9,40]$. Self-regulation skills was proposed to play an important role in moderating the effects of stress on health behaviours $[9,40]$, and thus, strengthening the self-regulation skills could help to decrease SES differences in health behaviours. In addition, previous studies suggested that the effects of an intervention might be higher when including strengthening of self-regulation skills along with promoting healthy EBRBs $[10,13]$.

\section{Mediating factors between SES and children's EBRBs}

In mediation analyses, the data from the DAGIS crosssectional survey was used. As the found SES differences 
in children's EBRBs were related to parental educational level, the mediation analyses used parental educational level as the independent variable and children's screen time and sugary food and drink consumption as dependent variables. Testing for mediation factors yielded following mediators, which have been published elsewhere [41]: 1) parents' views on acceptable screen time for children, 2) their own screen use in front of their child, 3) importance they place on limiting child's screen time, and 4) feelings of societal pressures to use screens. In not so far published analysis, the associations between parental education and sugary food and drink consumption were mediated by: 1) availability of these foods at home, and 2) parents' views on acceptable consumption frequency of these foods and drinks (not published).

Literature on mediators between SES and preschoolers' EBRBs is scarce. One study showed that parental television viewing and having a television in the child's bedroom mediated the associations between parental SES and children's screen time [39]. The availability of, and the parent's permissiveness towards consumption of sugary foods and drinks, as well as the parent's self-efficacy to serve water instead of soft drinks were in one study identified as significant mediators for association between SES and sugary food and drink consumption [42].

\section{Theoretical underpinnings of the DAGIS intervention}

To influence children's EBRBs, the behaviours of the adults around the children must be addressed. Therefore, there was also a focus on theories that were important for changing the behaviours of the adults. The Social Cognitive Theory (SCT) [43], Theory of Planned Behaviour (TPB) [44], and Self-Determination Theory (SDT) [45] were chosen as the framework for the intended behaviour changes in adults and further on in children's EBRBs (see Additional file 1: Figure S1). The reason for choosing these theories is twofold. Firstly, many central components in the above-mentioned theories were identified in the focus group interviews that took place in 2014, and they were found to be significant mediators in the associations between parental education and children's EBRBs in the DAGIS cross-sectional study data [41] Secondly, these behaviour change theories have been shown to be practical tools to conceptualize behaviour change, and their application has in intervention studies yielded actual behaviour change [46, 47].

\section{Development of the DAGIS logic model of change}

Based on the findings from the survey and the literature review, three programme objectives for changing children's EBRB and self-regulation skills were defined (see the secondary outcomes in Table 1). Objectives were formulated so that the intervention did not only pursue to decrease unwanted EBRBs by reducing screen time, and sugary foods and drinks consumption, but also to influence beneficial EBRBs by increasing PA, and fruit and vegetable consumption. By promoting beneficial EBRBs, families were approached also with a positive encouraging message. The intention to change is more likely when you think that advantages outweigh disadvantages [44]. The last objective to strengthen children's self-regulation skills was formed based on the literature findings that linked children's weight and EBRBs with their self-regulation skills $[2,9,40]$.

Further, the most important mediators between family SES and children's EBRBs in the DAGIS survey were parents as role models, and the availability and accessibility of screens and sugary foods ( [38] and unpublished results). Guided by the theoretical underpinnings and findings from the needs assessment, we further defined determinants that we needed to influence in order to change the behaviour of children (see the primary outcomes in Table 1). Based on these results and the theoretical underpinnings, the DAGIS logic model of change was developed (Table 1). Children's EBRBs, which are the behaviours the DAGIS intervention aims to change, form the secondary outcomes. The primary outcomes are behaviours or activities in adults that need to be changed in order to have a change in children's EBRBs and self-regulation skills. The primary outcomes include intermediate and short-term outcomes. The intermediate outcomes are those determinants that in the survey, independently of the behavioural outcome, were mediators in the associations between parental SES and children's EBRBs. The short-term outcomes were determinants derived from both the mediator analyses of the DAGIS survey, and from behavioural theories.

\section{Results in steps 3 and 4: designing the DAGIS intervention programme and producing programme materials \\ Programme themes, components, and scope}

Programme themes founded were supporting children's self-regulation skills, increasing PA and intake of fruits and vegetables, and decreasing screen time and intake of sugary foods and drinks. Most evident socio-economic differences were in the needs assessment found in EBRBs that do not occur at preschools, but in the home environment, or are factors related to parenting practices. This fact resulted in a decision to develop a component with a substantial amount of materials for parents. The decision was supported by the literature that suggests that a high level of parental involvement is an essential part of effective interventions in changing children's EBRBs $[47,48]$. Further, we wanted to have an intervention component implemented at preschool. In Finland, supporting self-regulation is one of the main goals in 
Table 1 The DAGIS logic model of change

\begin{tabular}{|c|c|c|c|c|c|}
\hline \multirow[t]{2}{*}{ Inputs } & \multirow[t]{2}{*}{ Activities } & \multicolumn{2}{|c|}{ Primary outcomes, in adults 2017-2018 } & \multirow[t]{2}{*}{ Secondary outcomes, in children 2017-2018 } & \multirow{2}{*}{$\begin{array}{l}\text { Long-term } \\
\text { outcomes } \\
\text { (for children) }\end{array}$} \\
\hline & & Short term & Intermediate & & \\
\hline $\begin{array}{l}\text { Research } \\
\text { personel }\end{array}$ & Preschools & $\begin{array}{l}\text { Changes: } \\
\text { Norms about screen time } \\
\text { \& sugary everyday foods } \\
\text { and drinks }\end{array}$ & $\begin{array}{l}\text { Changes: } \\
\text { Role } \\
\text { modelling }\end{array}$ & $\begin{array}{l}\text { Excessive screen time diminishes \& Physical } \\
\text { activity (PA) increases }\end{array}$ & $\begin{array}{l}\text { Prevalence of } \\
\text { overweight } \\
\text { decreases }\end{array}$ \\
\hline \multirow[t]{2}{*}{ Funding } & \multirow[t]{2}{*}{$\begin{array}{l}\text { Group component for } \\
\text { parents, preschool } \\
\text { personel \& children }\end{array}$} & Knowledge, & $\begin{array}{l}\text { Availability } \\
\text { and } \\
\text { accessibility }\end{array}$ & $\begin{array}{l}\text { Sugary foods and drinks consumption diminishes } \\
\& \text { Fruit and vegetable consumption increases, } \\
\text { changes to less sugary products }\end{array}$ & \multirow{6}{*}{$\begin{array}{l}\text { Wellbeing and } \\
\text { learning } \\
\text { abilities } \\
\text { increases }\end{array}$} \\
\hline & & Attitudes & & Self-regulation skills strengthens & \\
\hline Materials & Home component & Motivation, engagement & & & \\
\hline \multirow[t]{3}{*}{ Collaborators } & & Awareness & & & \\
\hline & & Skills and self-efficacy & & & \\
\hline & & Social support & & & \\
\hline
\end{tabular}

national curriculum for early childhood education and care [19]. Therefore, the component at preschools emphasized the promotion of self-regulation skills. Implementing a preschool component reassured that intervention themes, both self-regulation and EBRBs, will be discussed with children irrespective of their parents' interests. With a preschool component, we were also able to strengthen children's active participation, which was emphasized in the parents' and early educators' workshop discussions. They felt that parents who are harder to reach could be motivated, if the messages come from their own child, in addition to other materials aimed directly for the parents.

\section{Choosing behaviour-change methods and practical applications}

Once we identified our objectives for children's and adults' behaviour changes, we used lists provided by Bartholomew et al. [25] and Michie et al. [49] to define change targets and to find theory-based methods to guide behaviour changes (Table 2). Several behaviourchange methods were identified; among them were active learning, direct experience, providing information on behaviour-health links, mobilizing social networks, and providing social support. We used literature to guide the selection of behaviour-change methods. Literature findings suggested that effective interventions more commonly used techniques prompting specific goal setting, environmental restructuring [50], providing general information on behaviour-health links, and social support $[51,52]$.

The behaviour-change methods were converted into practical strategies (Table 2). Information from similar interventions, results from the workshops, and existing materials produced by other organizations were used. For example, the workshop discussions emphasized the importance of sense of community, active participation of children, mutual fun activities for parents and children, and more communication between early educators and parents about skills practiced at preschools. Based on the aforementioned comments, several levels were decided to be included in the intervention (see Table 2). Also a shared preschool and family level was included, and early educators were instructed to organize activity afternoons at the preschool. At these afternoons parents and children together would conduct different theme activities. The afternoons created a possibility for parents to discuss the themes with other parents and early educators. During the afternoons, the early educators were also able to make visible for parents the themes covered and skills practiced at the preschool.

\section{Designing the programme, content, and materials for preschools and families}

Because we had chosen to develop a preschool-based intervention that involved families, we needed to develop a programme that had content for both preschools and families. For the preschool component, a core international programme, the MindU $\mathrm{p}^{\mathrm{Tm}}$ curriculum, was chosen [53]. The MindUp $\mathrm{p}^{\mathrm{mw}}$ curriculum has its foundations in theory and research on cognitive developmental neuroscience, mindfulness, and positive psychology [54]. The curriculum aims to develop self-awareness, self-management, and self-regulation. Many activities in the programme relate to physical activity and food. In Finland, MindUp ${ }^{\text {тм }}$ has been applied in multiple preschools. DAGIS researchers have been involved in evaluating the implementation of the MindUp ${ }^{\text {TM }}$ in preschools (not published), and through the early educators evaluation, we received valuable knowledge of best practices for adapting and implementing the curriculum. The core activity in the curriculum is the short relaxation moment, which is conducted three times daily in the 
Table 2 Practical strategies, methods and behaviour-change targets of the DAGIS intervention programme in accordance with the IM protocol $^{\mathrm{a}}$

\begin{tabular}{|c|c|c|c|}
\hline Intervention level & Practical strategies & Behaviour-change methods & Change target \\
\hline \multirow[t]{9}{*}{ Preschool } & \multirow[t]{5}{*}{ Early educators' trainings } & $\begin{array}{l}\text { Information about social and } \\
\text { environmental consequences }\end{array}$ & Attitude \\
\hline & & Framing $^{\mathrm{b}}$ & Attitude \\
\hline & & $\begin{array}{l}\text { Information on how to perform } \\
\text { the behaviour }{ }^{b}\end{array}$ & $\begin{array}{l}\text { Skills, capability, } \\
\text { self-efficacy }\end{array}$ \\
\hline & & Verbal persuasion about capability ${ }^{b}$ & $\begin{array}{l}\text { Skills, capability, } \\
\text { self-efficacy }\end{array}$ \\
\hline & & Mobilizing social networks ${ }^{a}$ & Social influence \\
\hline & Manuals & $\begin{array}{l}\text { Information on how to perform } \\
\text { the behaviour }{ }^{\text {b }}\end{array}$ & $\begin{array}{l}\text { Skills, capability, } \\
\text { self-efficacy }\end{array}$ \\
\hline & Meeting with preschool managers & Discussion $^{a}$ & $\begin{array}{l}\text { Motivation } \\
\text { Knowledge }\end{array}$ \\
\hline & Mentoring visits & $\begin{array}{l}\text { Discussion }^{a} \\
\text { Social support (practical) })^{b}\end{array}$ & $\begin{array}{l}\text { Knowledge Motivation } \\
\text { Capability }\end{array}$ \\
\hline & Booster e-mails with pedagogical tips & $\begin{array}{l}\text { Information on how to perform } \\
\text { the behaviour }{ }^{\text {b }}\end{array}$ & $\begin{array}{l}\text { Motivation } \\
\text { Skills, capability }\end{array}$ \\
\hline \multirow[t]{2}{*}{ Preschool \& family } & \multirow[t]{2}{*}{ Activity afternoon } & Active learning $^{a}$ & Attitude \\
\hline & & Mobilizing social support & Social influence \\
\hline \multirow[t]{9}{*}{ Family } & \multirow[t]{6}{*}{ Educational letters \& DAGIS e-mails } & Persuasive communication ${ }^{a}$ & Attitude \\
\hline & & Prompting goal setting ${ }^{a}$ & Skills, capability \\
\hline & & $\begin{array}{l}\text { Information on how to perform } \\
\text { the behaviour }^{\text {b }}\end{array}$ & Skills, capability \\
\hline & & Restructuring the physical environment $^{b}$ & Skills, capability \\
\hline & & Identification of self as role model ${ }^{b}$ & Awareness \\
\hline & & $\begin{array}{l}\text { Normative information about } \\
\text { other's behaviour }\end{array}$ & $\begin{array}{l}\text { Social influence/ } \\
\text { social norm }\end{array}$ \\
\hline & \multirow{2}{*}{$\begin{array}{l}\text { Personal feedback on children's } \\
\text { measured EBRBs and information } \\
\text { about the measured average of } \\
\text { study participants' behaviours }\end{array}$} & Feedback $^{a}$ & $\begin{array}{l}\text { Awareness } \\
\text { Motivation }\end{array}$ \\
\hline & & $\begin{array}{l}\text { Normative information about } \\
\text { other's behaviour }\end{array}$ & $\begin{array}{l}\text { Social influence/ } \\
\text { social norm }\end{array}$ \\
\hline & Map application & Social support ${ }^{3}$ & Social influence \\
\hline \multirow[t]{2}{*}{ Family and child } & \multirow[t]{2}{*}{ Bingo board } & Active learning $^{a}$ & Skills, capability \\
\hline & & Direct experience ${ }^{a}$ & Attitudes \\
\hline \multirow[t]{7}{*}{ Child } & \multirow[t]{4}{*}{ MindU $p^{\mathrm{TM}}$ curriculum } & Guided practice $^{\mathrm{a}}$ & Skills, capability \\
\hline & & $\begin{array}{l}\text { Improving physical and } \\
\text { emotional states }^{\mathrm{a}}\end{array}$ & Skills, capability \\
\hline & & Active learning $^{a}$ & Skills, capability \\
\hline & & Using imagery ${ }^{a}$ & Knowledge \\
\hline & Activities related to EBRBs & Active learning ${ }^{a}$ & Skills, capability \\
\hline & \multirow[t]{2}{*}{ Storybooks } & Modeling $^{a}$ & Skills, capability \\
\hline & & Using imagery ${ }^{a}$ & Knowledge \\
\hline
\end{tabular}

Bartholomew et al. [25, 32]

${ }^{\mathrm{b}}$ Michie et al. [49]

preschools. The curriculum did not address all the determinants that we had identified as important and aimed to change through the DAGIS intervention. Thus, additional materials and activity ideas were developed, such as two storybooks and several manuals. Some materials were adapted from other existing materials that promote healthy EBRBs $[55,56]$. The family materials included some issues about children's selfregulation from the Mind $\mathrm{Up}^{\mathrm{Tm}}$ themes. However, in the family materials, we focused on issues that are relatively 
hard to change by preschools (e.g. children's screen time, consumption of sugary foods and beverages) (occurred at home, unpublished results from the survey). The practical strategies and contents are presented in more detail in Table 3.

The methods and the materials, such as encouraging low-budget family activities, were designed for the needs of low SES families. At this stage, we used knowledge from previous studies in the Nordic countries $[57,58]$, and we used the knowledge we had gathered through the focus groups in the autumn of 2014 $[28,29]$ and workshops in the autumn of 2016. We had workshops with the DAGIS steering group during 2016 and 2017, which yielded valuable knowledge about methods and materials appealing to low SES families. All these materials and methods were integrated with MindUp ${ }^{\mathrm{m}}$ themes and into a schedule to form the DAGIS intervention programme (Table 3 and Fig. 1).

\section{Feasibility testing and refinement of methods and materials}

The interviews, conducted as a part of the feasibility testing, yielded knowledge about the early educators' readiness for engaging with the materials and methods, their perceptions of the materials, how they had implemented the tested methods and materials, the interaction with parents about the materials sent home to families, and ideas that would promote the usability of the materials. Tested materials and methods were revised based on the feedback from parents and early educators during summer 2017. For example, the early educators suggested that the storybook should include a nursery rhyme in order to make the story more alive and easier to remember for the children. Another example was that early educators emphasized that it was important that they clearly knew the purpose and the aim of the materials and methods (such as materials, which will raise parents' awareness or knowledge about EBRBs', or methods which will engage children in PA etc), so that they could integrate and adapt the materials and methods in the best possible way. Revisions were made in the plans for the early educators' training, and in the early educators' manuals, so that the aims were explained more thoroughly. Members of the DAGIS research group visited a preschool in which MindUp ${ }^{\mathrm{Tm}}$ had been applied for 2 years, and the preschool manager and early educators elaborated on their experiences in implementing the curriculum. They gave ideas about how to support the implementation. Early educators mentioned that more tangible activity ideas is needed when implementing the MindUp ${ }^{\text {Tw }}$ the curriculum, because they always have a lack of planning time. As a result, we gathered additional suitable activity ideas, methods, how to enhance self-regulations skills, and how to combine it with the promotion of EBRBs'.

\section{Results in step 5: planning adoption and implementation of the DAGIS intervention programme}

The implementation plan for the DAGIS programme was developed in tandem with the programme design. The DAGIS steering group provided perspectives on how to engage the managers and early educators in the programme implementation and adoption. For example, they provided ideas about things and topics worth highlighting when communicating with managers and educators. The implementers for the DAGIS programme were preschool managers and early educators alongside the families (see Table 3). The implementation of the preschool component included three important methods: 1 ) appointing programme coordinators which were part of the research group, 2) organizing trainings for the early educators and managers in the intervention preschools, and 3) organizing a mentoring meeting for preschool managers and conducting mentoring visits in every intervention preschool group. To aid programme implementation, two coordinators supported preschool managers and early educators to implement programme activities at the preschools. Coordinators organized and carried out the early educators' trainings as well as the mentoring visits. Further, the coordinators sent booster e-mails with additional activity ideas and tips to keep connected with preschool groups and boost the programme implementation.

Early educators' trainings were organized at two different time points: before the programme start as two separate sessions lasting $6.5 \mathrm{~h}$ in total, and halfway through the programme as one training session lasting $3.5 \mathrm{~h}$ (see Fig. 1 and Table 3).

Teacher trainings have been used as one intervention strategy in many previous obesity-prevention/healthpromotion interventions conducted in school or preschool settings [59-61]. Trainings have been shown to be important for the adoption of interventions and also suggested to be an essential element for successful interventions $[46,62]$. The first training sessions covered the background and the aims of the programme, a knowledge-enhancing part that included EBRBs and how brains work and react and materials for the first three themes of the programme. The second part of the training covered a short repetition of the programme aims and background, perspectives from positive psychology and pedagogy, knowledge-enhancing EBRBs and materials for the last two themes of the programme. We chose to organize the trainings at two separate time points. We acknowledged that it was easier for the early educators to internalize the content and materials if it was split into two training sessions. Further, for example, Davis et al. [63] and Hoelscher et al. [64] have 
Table 3 Practical strategies, their contents and implementation

\begin{tabular}{|c|c|c|c|}
\hline Intervention level & Practical strategies & Strategy contents & Implementation \\
\hline \multirow[t]{3}{*}{ Preschool } & Early educators' trainings & $\begin{array}{l}\text { Intervention aims, timetable, materials } \\
\text { and theoretical background } \\
\text { Group discussions on intervention } \\
\text { implementation } \\
\text { Manuals were distributed, and their } \\
\text { contents were scrutinized } \\
\text { Based on MindUp }{ }^{\text {TM }} \text { training }\end{array}$ & $\begin{array}{l}\text { Before the intervention started, all early } \\
\text { educators participated in 5-5.5-h training; } \\
\text { at the halfway point of the intervention, } \\
\text { the early educators participated in an } \\
\text { additional } 2.5-3-\mathrm{h} \text { training }\end{array}$ \\
\hline & Manuals & $\begin{array}{l}\text { Short theoretical introduction to the } \\
\text { contents of the theme } \\
\text { Activity ideas to do with children at } \\
\text { preschool } \\
\text { Connection of the theme and activities } \\
\text { to the national core curriculum for early } \\
\text { education and care } \\
\text { Materials that should be distributed to } \\
\text { parents during the theme period }\end{array}$ & $\begin{array}{l}\text { One manual for each theme (altogether } \\
\text { five themes) was distributed during the } \\
\text { training sessions }\end{array}$ \\
\hline & $\begin{array}{l}\text { Meeting with preschool } \\
\text { managers }\end{array}$ & $\begin{array}{l}\text { Informal meeting aiming to recognize } \\
\text { the problems that preschools might } \\
\text { have with programme implementation } \\
\text { Meeting informed the researchers how }\end{array}$ & $\begin{array}{l}\text { Was organized } 2 \text { weeks after early educators } \\
\text { trainings; managers from all intervention } \\
\text { preschools gathered together in the town } \\
\text { hall where the meeting was held }\end{array}$ \\
\hline
\end{tabular}

Mentoring visits

Booster e-mails with pedagogical tips

Preschool and family Activity afternoons

Educational letter

DAGIS e-mails

Personal feedback each of the preschools preferred the mentoring visits to be organized

Varied slightly according to the needs/ wishes of the early educators and manager: either an organized meeting with early educators and manager or free discussion only with early educators in each group about how the intervention implementation had started

Reminder that a new theme was supposed to be started at preschools

Additional practical activity ideas about how the theme could be discussed with children at preschool

Included activities that were related to the ongoing theme and that parents could do together with their children; all activities were such that the children had practiced the things at preschool before the afternoon and could show their parents how to do the activities

General information on target behaviour of the theme: how the behaviour benefits health, increases skills and supports family life Tips for how to perform behaviour (e.g. increase PA as a family, increase fruit and vegetable consumption, decrease sugar intake, regulate children's screen use) Information on the recommendations and normative information on the behaviours on average (e.g. average screen time or fruit and vegetable consumption of the study participants) Normative information on how other parents on average try to support the health behaviour in question

Included links to existing materials on the internet regarding the theme that was ongoing at that moment

Two of the e-mails included video clips related to the theme

Personal feedback on child's EBRBs based on the baseline measurements; alongside personal results, the averages of the study
Were organized 2-3 weeks after the intervention start at the preschools

Were sent at the beginning of each new theme

Were organized at preschools by early educators; one activity for each EBRB theme

Were distributed to parents in paper through the preschool; one for each theme

Were sent to families through the preschool; one for each theme

Were sent directly to participants by researchers; one for each theme 
Table 3 Practical strategies, their contents and implementation (Continued)

\begin{tabular}{|c|c|c|c|}
\hline Intervention level & Practical strategies & Strategy contents & Implementation \\
\hline & & cohort were presented & \\
\hline & Map application & $\begin{array}{l}\text { A map application where: } \\
\text { Children and parents could tag their } \\
\text { favourite places to be physically active } \\
\text { and that they would recommend to } \\
\text { other families } \\
\text { Early educators could tag activity places } \\
\text { where the group had visited during the } \\
\text { preschool day and share the places with } \\
\text { parents } \\
\text { Early educators could create orienteering } \\
\text { maps for themselves as well as for other } \\
\text { groups }\end{array}$ & $\begin{array}{l}\text { Was presented to parents by early } \\
\text { educators during the screen-time-related } \\
\text { theme }\end{array}$ \\
\hline Family and child & Bingo board & $\begin{array}{l}\text { Bingo board including fun activities that } \\
\text { parents and children could try together } \\
\text { at home }\end{array}$ & $\begin{array}{l}\text { Were distributed to parents as a part of } \\
\text { the educational letter }\end{array}$ \\
\hline \multirow[t]{3}{*}{ Child } & MindU ${ }^{\mathrm{TM}}$ curriculum & $\begin{array}{l}\text { The curriculum aims to develop self- } \\
\text { awareness, self-management, and } \\
\text { self-regulation through attention } \\
\text { awareness practices and lessons. } \\
\text { Several activities include physical activity } \\
\text { and eating (Maloney et al. 2016) } \\
\text { (e.g. children were taught how the brain } \\
\text { works by using fictive animal figures, and } \\
\text { being mindful in their physical activity) }\end{array}$ & Was implemented in the preschool groups \\
\hline & Activities related to EBRBs & $\begin{array}{l}\text { Sensory-based activities and other activities } \\
\text { related to fruit and vegetables } \\
\text { Games and other activities (e.g. physically } \\
\text { active Christmas calendar) to increase PA }\end{array}$ & Were implemented in the preschool groups \\
\hline & Two storybooks & $\begin{array}{l}\text { One of the storybooks was about the } \\
\text { balance between inactivity and PA; the } \\
\text { other storybook was about being brave } \\
\text { with tasting food. } \\
\text { At preschool, the stories were meant to } \\
\text { be read with the whole group and } \\
\text { adjusted for the group's age; both } \\
\text { stories included pictures, which made } \\
\text { it possible to go through the stories } \\
\text { using only the pictures }\end{array}$ & $\begin{array}{l}\text { Were distributed to each preschool group } \\
\text { as well as every family; family storybooks } \\
\text { were attached to their educational letters }\end{array}$ \\
\hline
\end{tabular}

suggested that organizing trainings at several time points supports the implementation of programmes. Early educators' manuals, including instructions and activity ideas for each theme, and supporting materials, were disseminated at the training sessions.

A meeting with all preschool managers was organized soon after the initial intervention trainings (Table 3). The aim was to hear preschool managers' views on how early educators in their preschools accepted the programme and what kind of support could help them to get started with the programme. Additionally, reinforcing managers' roles in supporting the programme implementation was on the meeting agenda, as managers' role has been recognized as essential for successful implementation of programmes [65]. Coordinators visited each preschool group after 3-5 weeks from the programme start. These mentoring visits differed slightly between the groups according to the needs and wishes of the preschool. In some preschools, the coordinator visits were informal observation and discussion visits, while the early educators and children continued their normal tasks and routines in the preschool group. In some preschools, visits were organized as more formal meetings, having one person from each group participating in the meeting. The purpose of the meetings was to support early educators in the programme start.

The implementation of the programme at the family level included several methods (Table 3 ). The activity afternoons enhanced the interaction between the parents and between parents and the preschool personnel. Throughout the programme, families were reached through traditional educational letters produced in the DAGIS programme and distributed by the preschools to the families. Short e-mails about the programme themes were sent out through preschool e-mail lists. By using short videos in the e-mails, for example, the programme aimed to catch those parents who might have been less interested in reading educational letters. The implementation of the programme was also achieved by giving personal feedback on the children's 


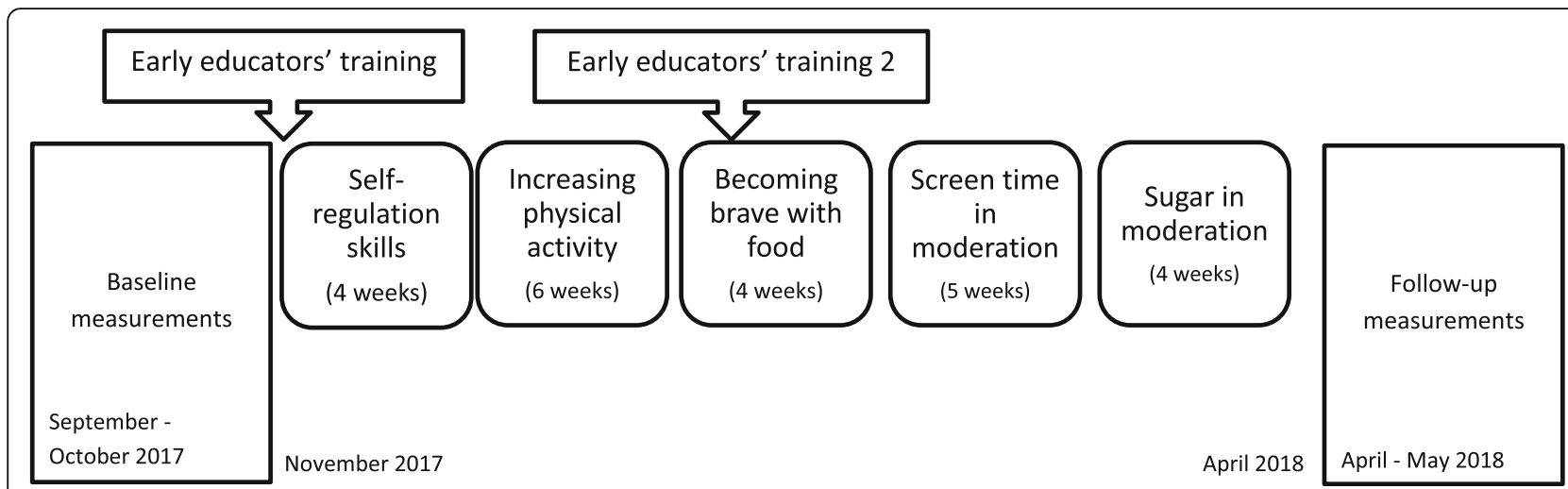

Fig. 1 Time' and themes of the DAGIS intervention programmes

EBRBs based on results from the baseline measurements and by distributing a map application where families could mark and share with other intervention families their favourite places to be physically active outdoors. Additionally, the preschool personnel used the map application to share with families the outdoor places that the preschool group visited during preschool time.

\section{Results in step 6: evaluation of the DAGIS intervention} The evaluation of the DAGIS intervention was planned in tandem with the development of the DAGIS programme. The evaluation was planned to answer two main questions:

1. Did the conducted DAGIS programme have an effect on the primary and secondary outcomes in the DAGIS logic model of change and did the conducted DAGIS programme diminish SES differences in children's EBRBs?

2. What were the processes in conducting the DAGIS programme like and how did the processes during the DAGIS intervention contribute to the project results?

In order to assess the effectiveness of the DAGIS programme, the evaluation included baseline and followup measurements, and it was planned to be conducted as a clustered randomized controlled trial (see Fig. 1). Preschools were planned to be randomized into intervention and control preschools after the baseline measurements. Power calculations showed that to be able to detect changes in children's EBRBs in three SES groups, at least 432 children needed to participate in the DAGIS RCT study.

The effectiveness measurements were planned to be done both among adults and children. The baseline and follow-up measurements for adults included questionnaires for preschool managers, early educators and parents. Early educators evaluated self-regulation skills by using the Attention and Executive Function Rating Inventory, ATTEX instrument [66]. Parents reported children's screen time at home by screen time diaries, and food consumption by electronic food frequency questionnaire (FFQ). Parent's questionnaires included assessments of SES and the primary outcomes from the DAGIS logic model of change. Additionally, they evaluated children's self-regulation skills by two instruments; the very short form Children's Behavior Questionnaire [30] and a short ten-statement instrument [67]. Children wore accelerometers (Actigraph wGT3X-BT) during seven consecutive days in order to measure PA levels.

The recruitment plans for the DAGIS intervention, the DAGIS logic model of change together with the practical strategies, and the implementation plans, formed the basis for the process evaluation planning. For evaluating the intervention the RE-AIM (reach, effectiveness/efficacy, adoption, implementation, and maintenance) framework and the evaluation tools which are available at the RE-AIM website were utilized [68]. All five REAIM dimensions were to some extent included in the process evaluation plan (Table 4). A higher degree of implementation generally yields higher effects [69]. Therefore, in the process evaluation plan, a comprehensive assessment of the implementation degree was emphasized to broaden the understanding of possible intervention effects. Also the context and the readiness of the implementers were assessed. These factors have been shown to be crucial for successful implementations [23, 70]. Additionally, to the tasks delivered from the tools of the RE-AIM framework, the comprehensive process evaluation included detailed questions about following: dose delivered (e.g. was material delivered?), dose received (e.g. was activity conducted?), quality (e.g. was activity conducted as intended?), participant responsiveness (e.g. satisfaction), programme differentiation (e.g. what was essential?), readiness to implement the intervention (e.g. motivation, attitudes and self-efficacy), and the context (e.g. barriers and facilitators). 
Table 4 The five RE-AIM (reach, efficacy/effectiveness, adoption, implementation, maintenance) dimensions and how these dimensions were planned to be measured through several components at different levels in the DAGIS intervention study

\begin{tabular}{|c|c|c|c|}
\hline $\begin{array}{l}\text { RE-AIM dimensions and the measured } \\
\text { components }\end{array}$ & $\begin{array}{l}\text { Measured at preschool } \\
\text { level (yes/no) }\end{array}$ & $\begin{array}{l}\text { Measured at parental } \\
\text { level (yes/no) }\end{array}$ & $\begin{array}{l}\text { Measured at child } \\
\text { level (yes/no) }\end{array}$ \\
\hline \multicolumn{4}{|l|}{ Reach } \\
\hline Inclusion criteria & yes & yes & yes \\
\hline Exclusion criteria & yes & yes & yes \\
\hline Sample size & yes & yes & yes \\
\hline Participation rate & yes & yes & yes \\
\hline Characteristics of nonparticipants & yes & no & no \\
\hline \multicolumn{4}{|l|}{ Efficacy/effectiveness } \\
\hline Measures of outcomes for one follow-up & yes & yes & yes \\
\hline Intention to treat analysis & yes & yes & no \\
\hline Quality of life measure & no & no & no \\
\hline $\begin{array}{l}\text { Measure of robustness across subgroups } \\
\text { (moderation analysis) }\end{array}$ & yes & yes & yes \\
\hline Percent attrition & yes & yes & yes \\
\hline \multicolumn{4}{|l|}{ Adoption } \\
\hline Description of intervention location & yes & no & no \\
\hline Description of staff who delivered intervention & yes & no & no \\
\hline Level of expertise of delivery agent & yes & no & no \\
\hline Adoption rate & yes & yes & no \\
\hline Use of qualitative data to understand adoption & yes & no & no \\
\hline \multicolumn{4}{|l|}{ Implementation } \\
\hline Intervention type and intensity & yes & yes & no \\
\hline Extent protocol delivered as intended & yes & yes & no \\
\hline Consistency of implementation & yes & yes & no \\
\hline Adoptions made to intervention during study & yes & no & no \\
\hline Barriers for implementation & yes & yes & no \\
\hline $\begin{array}{l}\text { Use of qualitative data to understand } \\
\text { implementation }\end{array}$ & yes & no & no \\
\hline \multicolumn{4}{|l|}{ Maintenance } \\
\hline $\begin{array}{l}\text { Program components continued at } 6 \text { months } \\
\text { following the completion of the intervention }\end{array}$ & yes & no & no \\
\hline Characteristics of those continuing the program components & yes & no & no \\
\hline $\begin{array}{l}\text { Program modifications after } 6 \text { months of } \\
\text { completion of the intervention }\end{array}$ & yes & no & no \\
\hline
\end{tabular}

The process evaluation targeted all essential stakeholders: preschool managers, early educators, parents, and children (Table 4). Preschools managers' follow-up questionnaires had slightly different questions depending on belonging to the intervention or control group. Early educators also filled out follow-up questionnaires-separate questionnaires for control and intervention preschools. Early educators in intervention preschools filled out questionnaires after each programme training at the baseline and in the middle of the intervention. Early educators from each group filled in weekly logbooks assessing conducted relaxation moments, other conducted
DAGIS intervention activities, and monthly activity afternoons arranged for parents. To get a deeper understanding of how managers and early educators perceived the DAGIS programme, interviews with all managers $(N=8)$ of intervention preschools and focus groups with early educators in six intervention preschools were conducted. The topics for the interviews were barriers and facilitators in implementing the DAGIS programme. The preschools chosen for the focus group were based on the motivation level for the programme at the baseline. The motivational level had been asked in a questionnaire at the first programme training for early educators. Two 
highly motivated, two middle-motivated, and two lowmotivated preschools were chosen. The quantitative and qualitative measurements of barriers and facilitators for implementation enables triangulation in the evaluation process to get a deeper understanding of the adoption and implementation of the DAGIS programme. The parents' questionnaire included process evaluation questions at follow-up. In addition, parents filled out an evaluation form at mid-intervention. Informal workshops were conducted with children in order to get a better understanding of children's experiences and understanding of the programme.

\section{Discussion}

The goal of this paper is to present the development process of the DAGIS intervention study aiming to decrease SES differences in children's EBRBs and selfregulation skills by a preschool-based family-involving intervention and using the IM protocol [25] as a guiding tool for the development process. The DAGIS intervention study used the proportionate universalism approach, which meant that the intervention was delivered to the whole target group with a special emphasis on those needing it the most [15]. The result was the DAGIS intervention study, which was developed and conducted as a preschool clustered RCT between September 2017 and May 2018.

The IM protocol served as an easily applicable guiding tool in the planning process, and the good applicability has also been reported by others [71]. However, there are both pros and cons in using the IM framework, which in planning the DAGIS intervention study led to compromises at some steps. The use of the IM framework can to some degree make the planning process in the beginning, steps 1 and 2, longer and more burdensome than expected. The same remarks about extensive time demands were previously reported by others [71-73]. Because of the limited time resources, the researchers in the development of the DAGIS intervention study were forced to make some compromises. The change matrices for performance objectives, which are presented in step 2 in IM, were not formed as guided. This led to a limitation because the DAGIS logic model of change was not completed so that it could be presented as a proper model of change. Creating the change matrices would have enabled the DAGIS intervention to form more detailed performance objectives, which in turn would have improved the evaluation process. Still, the DAGIS intervention model includes behavioural outcomes at the child level as well as the adult level. The behavioural outcomes at the adult level are driven by DAGIS analyses from the comprehensive survey and an informal literature review. The planning of the effectiveness evaluation has been relying on the questions derived from the DAGIS survey. The
DAGIS model also includes theory-driven personal determinants for adults' behaviours, and the effectiveness evaluation has included questions regarding these determinants that are important for children's EBRBs ( $[41,70]$, and unpublished results). Still, when evaluating the changing mechanisms for the effectiveness evaluation, a challenge might be that we did not create a matrix of change objectives. They point out the behaviour change that occurs when we want to change a determinant for the behaviour.

The developed DAGIS intervention study is, to the best of our knowledge, the first EBRB-promoting preschool intervention among children that applies the proportionate universalism approach [15]. It is a challenge to reach those who need it most, without stigmatizing any participants. One way to ensure that we had possibilities to reach children also from lower SES backgrounds, was to use the same method to invite municipalities to the intervention study, as was used in the survey: invite municipalities with as diverse a population as possible [74]. Having a whole municipality participating increased the possibilities of having children of all SES backgrounds. A Swedish research team applied the proportionated universalism by conducting a more intensive intervention in a deprived area than in other areas of Stockholm [75]. To apply the proportionate universalism approach in the DAGIS intervention study in that manner was challenging, due to that most preschools are mixed up with children from all kinds of SES backgrounds. Instead, we chose to develop a programme aimed to influence the most critical determinants for EBRBs in children with lower SES backgrounds. The determinants for children's EBRBs, which were included in the DAGIS logic model of change, were derived from the multiple mediation analyses between family SES and children's EBRBs. These were conducted in the first steps of the planning process (See chapter; Mediating factors between SES and children's health behaviour). We included in the logic model of change only those determinants that in our analyses showed to be important mediators for associations between lower family SES and children's EBRBs. By targeting those determinants in the DAGIS intervention, we aimed to change the critical determinants for lower SES family children, which will improve the lower SES children's EBRBs. In addition, when we designed the programme methods and materials, they were designed to the needs of lower SES families, such as encouraging low-budget family activities, or producing easy to read materials.

The development of the DAGIS intervention applying the IM protocol has its limitations. As previously discussed, the limited time directed into not applying all tasks at each step. Some of the DAGIS intervention 
study researchers had either theoretical knowledge or practical experience of applying the IM framework, which could have strengthened the planning process [76]. The evaluation planning process was not entirely in tandem with the planning process of the DAGIS intervention. Part of the planning was still running when the DAGIS programme started. This can be seen both as a limitation and a strength. Soon after the first DAGIS training for the early educators, it emerged that deeper knowledge was needed about how the preschool managers perceived their role in the DAGIS intervention, and what the barriers and facilitators were for early educators to implement the programme. As the evaluation planning was still running, we were able to add qualitative evaluation methods to the process evaluation. Deeper knowledge about the context for an appropriate process evaluation is also highlighted in the MRC guidelines for process evaluation of complex interventions [23]. Conducting interviews with all intervention preschool managers in the middle of the programme, and focus group interviews with early educators after the follow-up measurements, will strengthen the evaluation of the DAGIS intervention study.

\section{Conclusion}

To conclude, by applying the IM protocol in developing the DAGIS intervention study, a preschool-based familyinvolving programme was established. The development was time- and resource-consuming. Development started in 2014, and the intervention was conducted in September 2017 to May 2018. Applying the IM protocol had several advantages. The systematic planning, development, and running of the programme have reinforced a comprehensive evaluation that will enhance the knowledge of how to promote EBRBs and self-regulation skills among preschoolers and diminish SES differences in them.

\section{Supplementary information}

Supplementary information accompanies this paper at https://doi.org/10. 1186/s12889-019-7864-0.

Additional file 1: Figure S1. Theoretical underpinnings for adults as role models and actors for availability and accessibility in the DAGIS study. Theories adapted in the model: Social Cognitive Theory (Bandura [43]), Theory of Planned Behaviour (Ajzen [44]) and Self-determination Theory (Ryan and Deci 2000).

\section{Abbreviations}

DAGIS: Increased Health and Wellbeing in Preschools; EBRBs: Energy balancerelated behaviours; IM: Intervention Mapping; PA: Physical Activity; RCT: Randomized Controlled Trial; SCT: Social Cognitive Theory; SDT: Self Determination Theory; SES: Socio-economic status; TPB: Theory of Planned Behaviour

\section{Acknowledgements}

The authors thank the preschools, early educators and families for their participation in the DAGIS study and the early educators for the data collection.

\section{Authors' contributions}

$C R, R K, E L, H V$, NS, ME, and ER have participated in the needs assessment phase, the development, and the planning of the intervention. CR and RK wrote the manuscript, and prepared the tables and figures. EL prepared the supplementary figure. $C R, R K, E L, H V, N S, M E$, and $E R$ have actively participated in writing the manuscript and comment on it. The final manuscript is approved by all authors; CR, RK, EL, HV, NS, ME, and ER.

\section{Funding}

This study was financially supported by the Ministry of Education and Culture in Finland (2014-2016), The Ministry of Social Affairs and Health (2016-2018), The Academy of Finland (Grant: 285439, years 2016-2018), the Päivikki and Sakari Sohlberg foundation (2015-2018), and the Medicinska Föreningen Liv och Hälsa (2015-2019). Folkhälsan Research Center and University of Helsinki has provided the infrastructure and the funding for PIs (NS, ME, ER), and key personnel (CR). The funding bodies have not been not involved or interfere with the design of the study, collecting the data, analyzing the data from first phases in the project, developing the intervention, or in writing the manuscript.

\section{Availability of data and materials}

Researchers interested in the data and materials from this study may contact principal investigator Eva Roos, eva.roos@folkhalsan.fi

\section{Ethics approval and consent to participate}

The DAGIS intervention study was found to be ethically acceptable, as the recruitment process for participation, by the University of Helsinki Ethical Review Board in Humanities and Social and Behavioral Sciences in May 2017 (22/2017). The two directors for all the municipality driven preschools gave their informed written consent to participate by email. Preschool managers in the municipalities were by a site visit informed about the study. Early educators got an oral presentation about the study through their preschool managers, and additionally by researchers conducting site visits. Even though preschools were participating, it was voluntary for early educators to answering the questionnaires (during working time). By answering the questionnaires, early educators gave their informed consent to participate in the study. An informed consent was obtained from all participating families before the study started.

\section{Consent for publication}

Not applicable.

\section{Competing interests}

The authors declare that they have no competing interests.

\section{Author details}

${ }^{1}$ Folkhälsan Research Center, Topeliuksenkatu 20, 00250 Helsinki, Finland. ${ }^{2}$ Department of Food and Nutrition, University of Helsinki, P.O. Box 66, 00014 Helsinki, Finland. ${ }^{3}$ Department of Teacher Education, University of Helsinki, P.O. Box 9, 00014 Helsinki, Finland. ${ }^{4}$ Philosophical Faculty, School of Applied Educational Science and Teacher Education, University of Eastern Finland, P.O. Box 111, 80101 Joensuu, Finland. ${ }^{5}$ Department of Public Health, Clinicum, University of Helsinki, P.O. Box 63, 00014 Helsinki, Finland.

Received: 17 May 2019 Accepted: 29 October 2019

Published online: 12 December 2019

References

1. Viikari JS, Niinikoski H, Juonala M, Raitakari OT, Lagström H, Kaitosaari T, et al. Risk factors for coronary heart disease in children and young adults. Acta Paediatr Suppl. 2004;93(446):34-42.

2. Wilson SM, Sato AF. Stress and paediatric obesity: what we know and where to go. Stress Heal. 2014;30(2):91-102.

3. Veijalainen A, Tompuri T, Haapala EA, Viitasalo A, Lintu N, Väistö J, et al. Associations of cardiorespiratory fitness, physical activity, and adiposity with arterial stiffness in children. Scand J Med Sci Sport. 2016;26(8):943-50.

4. Mantziki K, Vassilopoulos A, Radulian G, Borys J-M, Du Plessis H, Gregorio MJ, et al. Inequities in energy-balance related behaviours and family environmental determinants in European children: baseline results of the prospective EPHE evaluation study. BMC Public Health. 2015;15:1203. 
5. De Craemer M, De Decker E, De Bourdeaudhuij I, Vereecken C, Deforche B, Manios Y, et al. Correlates of energy balance-related behaviours in preschool children: A systematic review. Obes Rev. 2012;Suppl 1:13-28.

6. Bingham DD, Costa S, Hinkley T, Shire KA, Clemes SA, Barber SE. Physical activity during the early years: a systematic review of correlates and determinants. Am J Prev Med. 2016;51(3):384-402.

7. Fernandez-Alvira J, Mouratidou T, Bammann K, Hebestreit A, Barba G, Sieri S, et al. Parental education and frequency of food consumption in European children: the IDEFICS study. Public Health Nutr. 2013;16(3):487-98.

8. Vliegenthart J, Noppe G, van Rossum EFC, Koper JW, Raat H, van den Akker ELT. Socioeconomic status in children is associated with hair cortisol levels as a biological measure of chronic stress. Psychoneuroendocrinology. 2016;65:9-14.

9. Aparicio E, Canals J, Arija V, De Henauw S, Michels N. The role of emotion regulation in childhood obesity: implications for prevention and treatment. Nutr Res Rev. 2016;29(1):17-29.

10. Lumeng JC, Miller AL, Horodynski MA, Brophy-Herb HE, Contreras D, Lee H, et al. Improving self-regulation for obesity prevention in head start: a randomized controlled trial. Pediatrics. 2017;139(5):e20162047.

11. Seeyave DM, Coleman S, Appugliese D, Corwyn RF, Bradley RH, Davidson NS, et al. Ability to delay gratification at age 4 years and risk of overweight at age 11 years. Arch Pediatr Adolesc Med. 2009;163(4):303-8.

12. Liang J, Matheson BE, Kaye WH, Boutelle KN. Neurocognitive correlates of obesity and obesity-related behaviors in children and adolescents. Int J Obes. 2014;38:494-506

13. Miller AL, Lumeng JC. Pathways of association from stress to obesity in early childhood. Obesity. 2018;26(7):1117-24

14. Biddle SJH, Petrolini I, Pearson N. Interventions designed to reduce sedentary behaviours in young people: a review of reviews. Br J Sports Med. 2014;48(3):182-6.

15. Marmot M. Proportionate universalism. In: The health gap- the challenge of an unequal world. 1st ed. London: Bloomsbury publishing; 2015. p. 279-89.

16. Hesketh KD, Campbell KJ. Interventions to prevent obesity in 0-5 year olds: An updated systematic review of the literature. Obesity. 2010;Suppl 1:s27-35.

17. Temple M, Robinson JC. A systematic review of interventions to promote physical activity in the preschool setting. J Spec Pediatr Nurs. 2014;19(4):274-84.

18. Säkkinen S, Kuoppala T. Varhaiskasvatus 2017 (Children's day care 2018). National Institute for Health and Welfare. http://urn.fi/URN:NBN:fi-fe20181 00937865. Accessed 21 Mar 2019.

19. Finnish National Agency for Education. National Core Curriculum for Early Childhood Education and Care 2016. 2016. Helsinki. http:/wwww.oph.i/english/curricula_and_ qualifications/early_childhood_education_and_care. Accessed 30 Aug 2019.

20. Valtion ravitsemusneuvottelukunta. Health and joy from food-food recommendations for early childhood education and care (Terveyttä ja iloa ruosta- varhaiskasvatuksen ruokailusuositus). Helsinki; 2018. http://urn.fi/URN: ISBN:978-952-343-033-4. Accessed 30 Aug 2019.

21. Joy, play and doing together- recommendations for physical activity in early childhood. Helsinki, Finland. http://urn.fi/URN:ISBN:978-952-263.410-8. Accessed 30 Aug 2019

22. Kok G, Gottlieb N, Peters G, Mullen P, Parcel G, Ruiter R, et al. A taxonomy of behaviour change methods: an intervention mapping approach. Heal Psychol Rev. 2016;10(3):297-312.

23. Moore GF, Audrey S, Barker M, Bond L, Bonell C, Hardeman W, et al. Process evaluation of complex interventions: Medical Research Council guidance. BMJ. 2015;19(359):h1258.

24. Durlak JA, DuPre EP. Implementation matters: a review of research on the influence of implementation on program outcomes and the factors affecting implementation. Am J Community Psychol. 2008;41:327-50.

25. Bartholomew Eldredge LK, Markham CM, Ruiter RAC, Fernandez ME, Parcel GS. Planning health promotion programs- an intervention mapping approach. Fourth Edi. San Fransisco: Jossey-Bass; 2016. p. 678.

26. Parikka S, Mäki $P$, Levälahti E, Lehtinen-Jacks S, Martelin T, Laatikainen T. Associations between parental BMI, socioeconomic factors, family structure and overweight in Finnish children: a path model approach. BMC Public Health. 2015;15:271.

27. Määttä S, Lehto R, Nislin M, Ray C, Erkkola M, Sajaniemi N, et al. Increased health and well-being in preschools (DAGIS): Rationale and design for a randomized controlled trial Health behavior, health promotion and society. BMC Public Health. 2015;15(1):402.

28. Määttä S, Ray C, Roos G, Roos E. Applying a Socioecological model to understand preschool Children's sedentary behaviors from the viewpoints of parents and preschool personnel. Early Child Educ J. 2016:44(5):491-502.
29. Ray C, Määttä S, Lehto R, Roos G, Roos E. Influencing factors of children's fruit, vegetable and sugar-enriched food intake in a Finnish preschool setting - preschool personnel's perceptions. Appetite. 2016;103:72-9.

30. Putnam SP, Rothbart MK. Development of short and very short forms of the Children's behavior questionnaire. J Pers Assess. 2006;87(1):102-12.

31. Lehto E, Ray C, Vepsäläinen $H$, Korkalo L, Lehto R, Kaukonen $R$, et al. Increased health and wellbeing in preschools (DAGIS) study-Differences in children's energy balance-related behaviors (EBRBs) and in long-term stress by parental educational level. Int J Environ Res Public Health. 2018;15(10):2313.

32. Bartholomew Eldredge LK, Markham CM, Ruiter RAC, Fernandez ME, Kok G, Parcel GS. Intervention mapping step 3: program design. In: Planning health promoting programs- an intervention mapping approach. 4th ed. San Fransisco: Jossey-Bass; 2016. p. 345-434.

33. Glasgow R. Evaluation of theory-based interventions. In: Glannz K, Rimer B, Viswanath K, editors. Health behaviour and health education:theory, research, and practice. 3rd ed. San Fransisco: Jossey-Bass; 2002. p. 530-44.

34. Dane AV, Schneider BH. Program integrity in primary and early secondary prevention: are implementation effects out of control? Clin Psychol Rev. 1998;18:23-45.

35. Linnan L, Steckler A. Process evaluation for public health interventions and research. San Fransisco: Jossey-Bass; 2002.

36. Baranowski T, Stables G. Process evaluations of the 5-a-day projects. Heal Educ Behav. 2000;27(2):157-66.

37. Erkkola M, Kronberg-Kippilä C, Kyttälä $P$, Lehtisalo J, Reinivuo $H$, Tapanainen $\mathrm{H}$, et al. Sucrose in the diet of 3-year-old Finnish children: sources, determinants and impact on food and nutrient intake. $\mathrm{Br} J$ Nutr. 2009;101:1209-17.

38. Kaikkonen R, Mäki P, Hakulinen-Viitanen T, Markkula J, Wikström K, Ovaskainen $M-L$, et al. Health and well-being inequalities among children and their families. Helsinki: National institute for health and wellfare (THL), Report 16/2012; 2012.

39. Wijtzes Al, Jansen W, Kamphuis CBM, Jaddoe WW, Moll HA, Tiemeier $H$, et al. Increased risk of exceeding entertainment-media guidelines in preschool children from low socioeconomic background: the generation $\mathrm{R}$ study. Prev Med (Baltim). 2012;55(4):325-9.

40. Vanaelst B, Michels N, Clays E, Herrmann D, Huybrechts I, Sioen I, et al. The association between childhood stress and body composition, and the role of stress-related lifestyle factors - cross-sectional findings from the baseline ChiBS survey. Int J Behav Med. 2014;21(2):292-301.

41. Määttä S, Kaukonen R, Vepsäläinen $H$, Lehto E, Ylönen A, Ray C, et al. The mediating role of the home environment in relation to parental educational level and preschool children's screen time: A cross-sectional study. BMC Public Health. 2017;17(1):688.

42. Pinket A, De Craemer M, De Bourdeaudhuij I, Deforche B, Cardon G, Androutsos $\mathrm{O}$, Koletzko $\mathrm{B}$, et al. Can parenting practices explain the differences in beverage intake according to socio-economic status: the Toybox-study. Nutrients. 2016;23(8):10.

43. Bandura A. Social foundations of thought and action : a social cognitive theory / Albert Bandura. Englewood Cliffs, N.J: Prentice-Hall; 1986.

44. Ajzen I. The theory of planned behavior: organizational behavior and human decision processes. Organ Behav Hum Decis Process. 1991;50(2):179-211.

45. Ryan RM, Deci EL. Self-determination theory and the facilitation of intrinsic motivation, social development, and well-being. Am Psychol. 2002;55:68-78.

46. Kreichauf $\mathrm{S}$, Wildgruber $\mathrm{A}$, Krombholz H, Gibson EL, Vögele C, Nixon CA, et al. Critical narrative review to identify educational strategies promoting physical activity in preschool. Obes Rev. 2012;13(Suppl. 1):96-105.

47. Sisson SB, Krampe M, Anundson K, Castle S. Obesity prevention and obesogenic behavior interventions in child care: a systematic review. Prev Med (Baltim). 2016;87:57-69.

48. Nixon CA, Moore HJ, Douthwaite W, Gibson EL, Vogele C, Kreichauf S, et al. Identifying effective behavioural models and behaviour change strategies underpinning preschool- and school-based obesity prevention interventions aimed at 4-6-year-olds: A systematic review. Obes Rev. 2012;13(Suppl. 1):106-17.

49. Michie S, Richardson M, Johnston M, Abraham C, Francis J, Hardeman W, et al. The behavior change technique taxonomy ( $v 1$ ) of 93 hierarchically clustered techniques: building an international consensus for the reporting of behavior change interventions. Ann Behav Med. 2013;46(1):81-95.

50. Golley RK, Hendrie GA, Slater A, Corsini N. Interventions that involve parents to improve children's weight-related nutrition intake and activity patterns - what 
nutrition and activity targets and behaviour change techniques are associated with intervention effectiveness? Obes Rev. 2011;12(2):114-30.

51. Hendrie GA, Brindal E, Corsini N, Gardner C, Baird D, Golley RK. Combined home and school obesity prevention interventions for children: what behavior change strategies and intervention characteristics are associated with effectiveness? Heal Educ Behav. 2012;39(2):159-71.

52. Hendrie GA, Lease HJ, Bowen J, Baird DL, Cox DN. Strategies to increase children's vegetable intake in home and community settings: a systematic review of literature. Matern Child Nutr. 2017;13(1):12276.

53. The Goldie Hawn Foundation. MindUP- Helping children thrive in school, work and life! Available from: https://mindup.org/. Accessed 7 Oct 2019.

54. Maloney JE, Stewart Lawlor M, Shonert-Reichl KA, Whitehead J. A universal, mindfulness-based social and emotional learning (SEL) program designed to be implemented in schools by regular classroom teachers. In: Shonert-Reichl KA, Roeser RW, editors. Handbook of mindfulness in education- integrating theory into practice. New York: Springer-Verlag; 2016. p. 313-34.

55. The Finnish Heart Association. Neuvokas perhe (Joy, enthusiasm and encouragement in lifestyle) Available from: https://neuvokasperhe.fi/en. Accessed 7 Oct 2019.

56. The Finnish Society on Media Education. https://mediakasvatus.fi/english/. Accessed 7 Oct 2019.

57. Nyberg G, Sundblom E, Norman Å, Bohman B, Hagberg J, Elinder LS. Effectiveness of a universal parental support programme to promote healthy dietary habits and physical activity and to prevent overweight and obesity in 6-year-old children: the healthy school start study, a cluster-randomised controlled trial. PLoS One. 2015;10(2):e0116876.

58. Elinder LS, Patterson E, Nyberg G, Norman Å. A healthy school start plus for prevention of childhood overweight and obesity in disadvantaged areas through parental support in the school setting - study protocol for a parallel group cluster randomised trial. BMC Public Health. 2018;18(1):459.

59. Bayer O, von Kries R, Strauss A, Mitschek C, Toschke AM, Hose A, et al. Short- and mid-term effects of a setting based prevention program to reduce obesity risk factors in children: a cluster-randomized trial. Clin Nutr. 2009;28(2):122-8.

60. Niederer I, Bürgi F, Ebenegger V, Marques-Vidal P, Schindler C, Nydegger A, et al. Effects of a lifestyle intervention on adiposity and fitness in overweight or low fit preschoolers (Ballabeina). Obesity. 2013;21 (3):E287-93.

61. Payr A, Birnbaum J, Wildgruber A, Kreichauf S, Androutsos O, Lateva M, et al. Concepts and strategies on how to train and motivate teachers to implement a kindergarten-based, family-involved intervention to prevent obesity in early childhood. The ToyBox-study. Obes Rev. 2014;15(Suppl 3):40-7.

62. Nathan N, Wolfenden L, Butler M, Bell AC, Wyse R, Campbell E, et al. Vegetable and fruit breaks in Australian primary schools: prevalence, attitudes, barriers and implementation strategies. Health Educ Res. 2011; 26(4):722-31.

63. Davis SM, Sanders SG, Fitzgerald CA, Keane PC, Canaca GF, Volker-Rector R. CHILE: an evidence-based preschool intervention for obesity prevention in head start. J Sch Health. 2013;83(3):223-9.

64. Hoelscher DM, Feldman HA, Johnson CC, Lytle LA, Osganian SK, Parcel GS, et al. School-based health education programs can be maintained over time: results from the CATCH institutionalization study. Prev Med (Baltim). 2004:38(5):594-606.

65. Ransford CR, Greenberg MT, Domitrovich CE, Small M, Jacobson L. The role of teachers ' psychological experiences and perceptions of curriculum supports on the implementation of a social and emotional learning curriculum. School Psych Rev. 2009;38(4):510-32.

66. Klenberg L, Tommo H, Jämsä S, Häyrinen T. Pienten lasten keskittymiskysely PikkuKesky. Käsikirja. (The attention and executive functions rating inventory ATTEX-P. handbook). Helsinki: Hogrefe Publishing Corp.; 2017.

67. Hogan AE, Scott KG, Bauer CR. The adaptive social behavior inventory (ASBI): a new assessment of social competence in high-risk three-year-olds. J Psychoeduc Assess. 1992;10(3):230-9.

68. RE-AIM workgroup. RE-AIM Improving public health relevance and population health impact. http://www.re-aim.org/. Accessed 7 Oct 2019.

69. De Craemer M, Verloigne M, De Bourdeaudhuij I, Androutsos O, lotova V, Moreno $L$, et al. Effect and process evaluation of a kindergarten-based, family-involved cluster randomised controlled trial in six European countries on four- to six-year-old children's steps per day: the ToyBox-study. Int J Behav Nutr Phys Act. 2017;14(1):116.
70. Saunders RP, Pfeiffer K, Brown WH, Howie EK, Dowda M, O'Neill JR, et al. Evaluating and refining the conceptual model used in the study of health and activity in preschool environments (SHAPES) intervention. Heal Educ Behav. 2017:44(6):876-84.

71. De Craemer M, De Decker E, De Bourdeaudhuij I, Verloigne M, Duvinage K, Koletzko B, et al. Applying the Intervention Mapping protocol to develop a kindergarten-based, family-involved intervention to increase European preschool children's physical activity levels: The ToyBox-study. Obes Rev. 2014;15(Suppl. 3):14-26.

72. Pérez-Rodrigo C, Wind M, Hildonen C, Bjelland M, Aranceta J, Klepp Kl, et al. The pro children intervention: applying the intervention mapping protocol to develop a school-based fruit and vegetable promotion programme. Ann Nutr Metab. 2005;49(4):267-77.

73. Mann CM, Ward DS, Vaughn A, Benjamin Neelon SE, Long Vidal L, Omar S, et al. Application of the intervention mapping protocol to develop keys, a family child care home intervention to prevent early childhood obesity. BMC Public Health. 2015;15:1227.

74. Määttä S, Ray C, Vepsäläinen H, Lehto E, Kaukonen R, Ylönen A, et al. Parental education and pre-School children's objectively measured sedentary time: The role of co-participation in physical activity. Int I Environ Res Public Health. 2018;15(2):366.

75. Burström B, Marttila A, Kulane A, Lindberg L, Burström K. Practising proportionate universalism - a study protocol of an extended postnatal home visiting programme in a disadvantaged area in Stockholm, Sweden. BMC Health Serv Res. 2017;17(91):1-8.

76. Lehto R, Maatta S, Lehto E, Ray C, Te Velde S, Lien N, et al. The PRO GREENS intervention in Finnish schoolchildren - the degree of implementation affects both mediators and the intake of fruits and vegetables. Br J Nutr. 2014;112(7):1185-94

\section{Publisher's Note}

Springer Nature remains neutral with regard to jurisdictional claims in published maps and institutional affiliations.

\section{Ready to submit your research? Choose BMC and benefit from:}

- fast, convenient online submission

- thorough peer review by experienced researchers in your field

- rapid publication on acceptance

- support for research data, including large and complex data types

- gold Open Access which fosters wider collaboration and increased citations

- maximum visibility for your research: over $100 \mathrm{M}$ website views per year

At BMC, research is always in progress.

Learn more biomedcentral.com/submissions 